\title{
Population-Based Epidemiologic Study on Herpes Zoster in Korea: Seven-Year Nationwide Analysis from 2010 to 2016
}

\author{
Soon-Hyo Kwon*, Jung-Im Na*, In Su Kim, Sang-Young Byun, Kyoung-Chan Park \\ Department of Dermatology, Seoul National University College of Medicine, Seoul, Department of Dermatology, Seoul National University \\ Bundang Hospital, Seongnam, Korea
}

Dear Editor:

Herpes zoster $(\mathrm{HZ})$ is caused by the reactivation of varicella zoster virus (VZV). Lowered VZV-specific cell-mediated immunity $(\mathrm{CMI})$ causes the reactivation of $\mathrm{VZV}^{1}$. The incidence of $\mathrm{HZ}$ is rapidly increasing worldwide, which may be caused by an aging population ${ }^{2}$. The purpose of the study was to evaluate the annual incidence and seasonality of $\mathrm{HZ}$ in the general population in Korea.

Data of patients with HZ between January 2010 and December 2016 were collected from Health Insurance Review and Assessment Service (HIRA) database ${ }^{3}$. Patients with at least one record of a diagnostic code (International Classification of Diseases-10, ICD-10) of B02.0 (zoster encephalitis), B02.1 (zoster encephalitis), B02.2 (Ramsay-Hunt syndrome), B02.3 (herpes zoster ophthalmicus), B02.7 (zoster with other complications), or B02.9 (herpes zoster) were included. Those who had a previous history of $\mathrm{HZ}$ were not excluded in this study. The study population was defined as the number of subscribers to the National Health Insurance Service (NHIS) during the study period. In addition, Google Trends data for 'herpes zoster' in Korean language were downloaded for further analysis of seasonality in $\mathrm{HZ}$ occurrence. The frequency of information-seeking behavior regarding the search term, 'herpes zoster,' ranged from 0 to 100. Available data from January 2012 to February 2018 were categorized into four seasons by calculat- ing the average value in three-month periods; spring (March to May), summer (June to August), fall (September to November), and winter (December to February). This study was exempted for a review by the institutional review board of Seoul National University Bundang Hospital in accordance with the exemption criteria (IRB no. $X-1407-257-902)$.

Of the total $4,232,576 \mathrm{HZ}$ patients during the study period, 1,666,937 were male and 2,565,539 were female (male:female $=0.65: 1$ ). The annual incidence of $\mathrm{HZ}$ steadily increased from 9.6 per 1,000 person-years (PY) in 2010 to 13.3 per $1,000 \mathrm{PY}$ in 2016 . While the number of medical insurance subscribers increased by 1,691,564 (3.3\%) from 50,581,191 in 2010 to $52,272,755$ in 2016, the number of $\mathrm{HZ}$ patients increased by 208,722 (43.0\%) from 485,544 to 694,266 . For those aged over 50 years, the number of $\mathrm{HZ}$ patients increased by 155,615 (57.7\%) while the number of medical insurance subscribers increased by $3,875,179(26.3 \%)$. Though the number of medical insurance subscribers aged under 50 years decreased by $2,183,615(6.7 \%)$ during the study period, the number of $\mathrm{HZ}$ patients increased by 53,107 (24.6\%). Fig. 1 demonstrates that the incidence of $\mathrm{HZ}$ steadily increased from 2010 to 2016 in all of the age groups. The age group of 70 to 79 years showed the most prominent increase in the incidence. The incidence of $\mathrm{HZ}$ increased with age,

\footnotetext{
Received May 25, 2018, Revised January 22, 2019, Accepted for publication January 22, 2019
}

Corresponding author: Kyoung-Chan Park, Department of Dermatology, Seoul National University Bundang Hospital, Seoul National University College of Medicine, 82 Gumi-ro 173beon-gil, Bundang-gu, Seongnam 13620, Korea. Tel: 82-31-787-7311, Fax: 82-31-787-4058, E-mail: gcpark@snu.ac.kr ORCID: https://orcid.org/0000-0002-1588-3307

*The two authors equally contributed to the article.

This is an Open Access article distributed under the terms of the Creative Commons Attribution Non-Commercial License (http://creativecommons.org/ licenses/by-nc/4.0) which permits unrestricted non-commercial use, distribution, and reproduction in any medium, provided the original work is properly cited.

Copyright (c) The Korean Dermatological Association and The Korean Society for Investigative Dermatology 


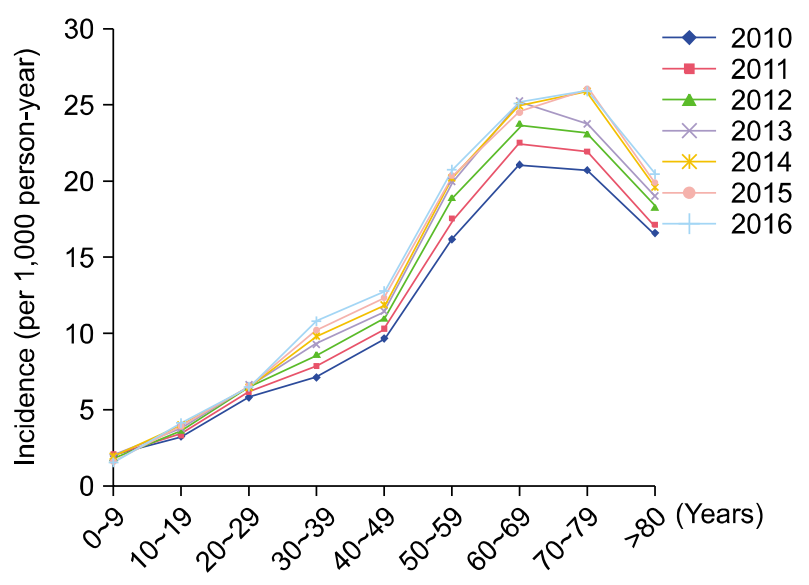

Fig. 1. The incidence of herpes zoster $(\mathrm{HZ})$ by the age groups between 2010 and 2016 in Korea. The incidence of HZ steadily increased from 2010 to 2016 in all of the age groups. The age group of 70 to 79 years showed the most prominent increase in the incidence. The incidence of $\mathrm{HZ}$ increased with age, which was the highest in the age group of 60 to 69 years during the period of 2010 to 2014. In the period of 2015 to 2016, however, the peak incidence shifted to the age group of 70 to 79 years. A rapid increase in the incidence of $\mathrm{HZ}$ was observed in the age group of 50 to 59 years. which was the highest in the age group of 60 to 69 years during the period of 2010 to 2014. In the period of 2015 to 2016 , however, the peak incidence shifted to the age group of 70 to 79 years.

Fig. 2A shows the seasonality with respect to the incidence of $\mathrm{HZ}$; it reached its peak in the summer season and lowest in the winter season. The number of patients in the spring, summer, fall, and winter seasons comprised of $24.0 \%, 27.2 \%, 25.8 \%$, and $22.9 \%$, respectively. Informationseeking behavior by analyzing Google search queries further revealed the seasonal pattern of $\mathrm{HZ}$ occurrence except in 2015 (Fig. 2B).

A previous epidemiologic study analyzing the HIRA database for a 5-year period also demonstrated a steady increase in the annual incidence of $\mathrm{HZ}$ from 7.93 per 1,000 PY in 2003 to 12.54 per 1,000 PY in $2007^{4}$. This value might be exaggerated since they included patients with postherpetic neuralgia. Nevertheless, the incidence results reported in Korea were considerably higher than that of other populations which were 4 to 6.24 per 1,000 $\mathrm{PY}^{2,5}$. The higher incidence in Korea could be attributed to the

A

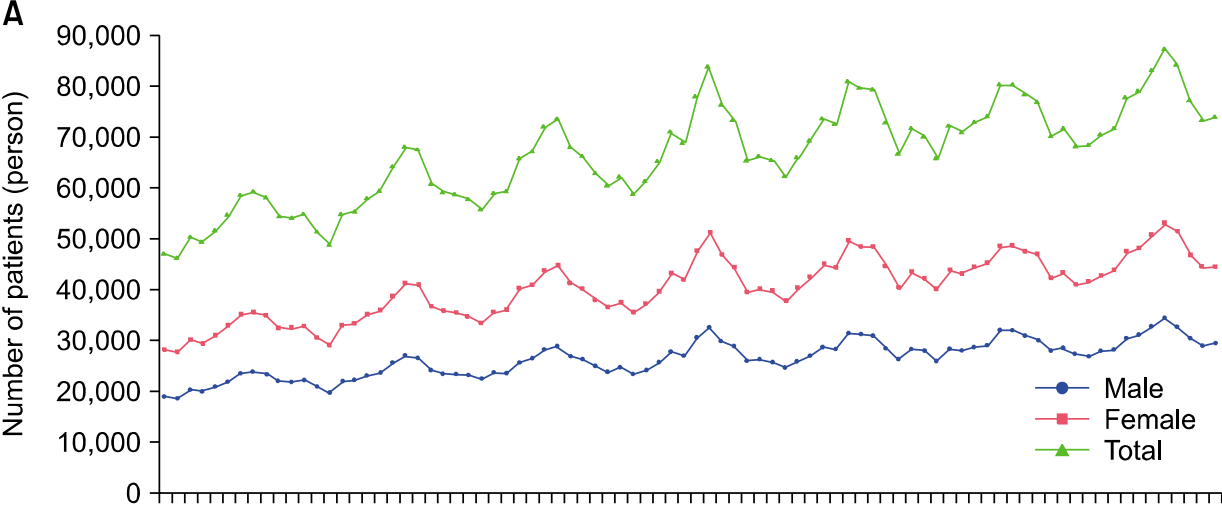

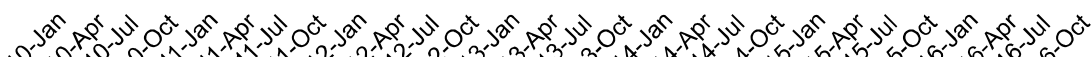

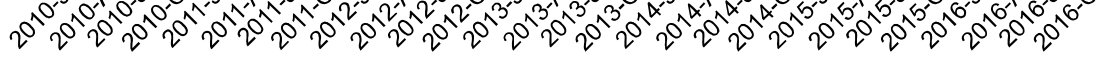

B

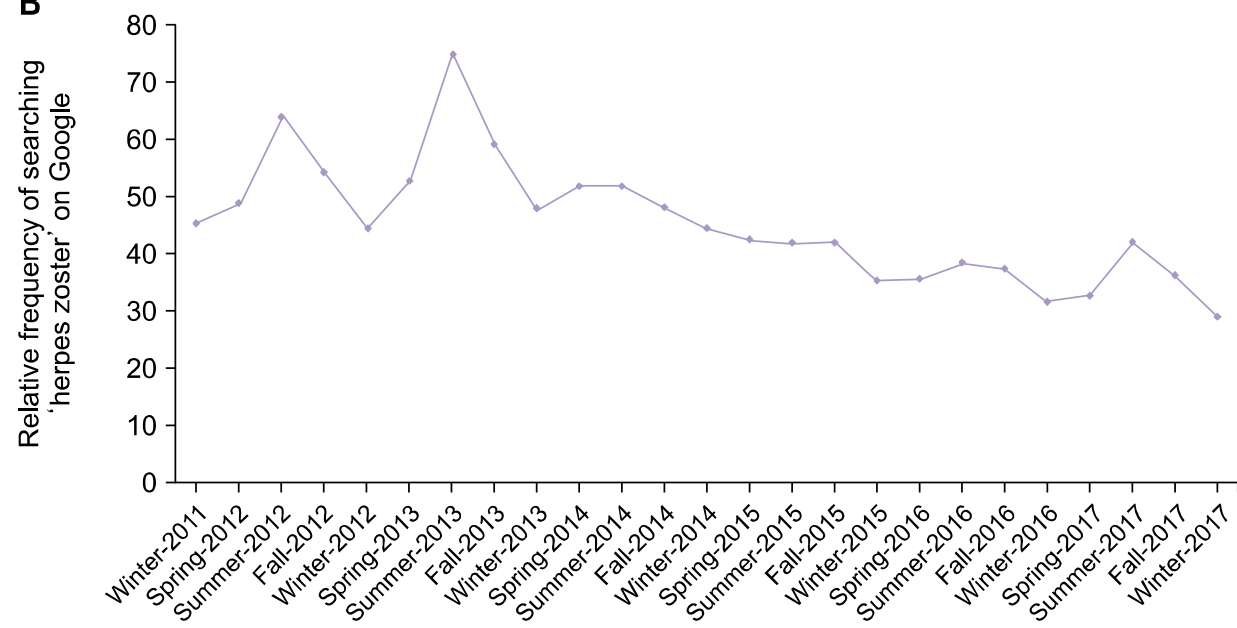

Fig. 2. (A) The seasonality of herpes zoster $(\mathrm{HZ})$ occurrence in Korea. The number of $\mathrm{HZ}$ patients presented a circannual pattern; it was increased during the spring season (March, April, and May), reaching its peak in the summer season (June, July, and August). Then the number of $\mathrm{HZ}$ patients decreased in the fall season (September, October, and November), reaching its lowest in the winter season (December, January, and February). (B) Google Trends data demonstrating informationseeking behavior for $\mathrm{HZ}$ in Korea. Except in 2015, information-seeking behavior showed the seasonal pattern; highest in the summer and lowest in the winter. 
medical service system, as it features mandatory enrollment of all citizens into NHIS with low medical cost burden and easy accessibility to medical services. Ethnic difference could also contribute to the higher incidence, although its genetic or environmental risk factor remains unknown.

Korean population is under a rapid aging, which is a wellknown risk factor for $\mathrm{HZ}$. There have been several reports on the association between the rise in $\mathrm{HZ}$ incidence and age $^{2}$. This correlation is readily explained by the progressive decline in VZV-specific CMI with aging ${ }^{1}$. However, an aging population solely could not explain the stead increase of the incidence of $\mathrm{HZ}$ in all of the age groups. Reduced chance of re-exposure to VZV is hypothesized to contribute to the lowered VZV-specific CMI in Korean population. Re-exposure to VZV might boost VZV-specific CMI to provide protection against $\mathrm{HZ}^{6}$. Introduction of universal VZV vaccination in 2005 has dramatically lowered the number of varicella patients in Korea, which decreased from 140,359 in 2010 to 79,321 in $2016^{3}$. A previous epidemiologic analysis revealed that the incidence of $\mathrm{HZ}$ was negatively associated with the incidence of varicella ${ }^{5}$.

The relationship between seasonality and incidence of $\mathrm{HZ}$ has been controversial. In contrary to the analysis of 1-year HIRA data, our study investigating 7-year HIRA and Google Trend data clearly demonstrated the seasonality of $\mathrm{HZ}$ occurrence ${ }^{7}$. A recent study clarified a strong association of the incidence of $\mathrm{HZ}$ with temperature and ultraviolet (UV) exposure ${ }^{5}$. Sunny hours during the summer increase exposure to UV irradiation, inducing immune suppression and VZV reactivation from latency ${ }^{8}$.

The limitation of this study is the absence of validation of the $\mathrm{HZ}$ diagnosis. A recent study revealed that the positive predictive value of $\mathrm{HZ}$ diagnosis based on ICD-10 was $86.2 \%$ by reviewing medical chart ${ }^{9}$. Defining the $\mathrm{HZ}$ diagnosis as a presence of disease code for $\mathrm{HZ}$ with at least 5-day use of antiviral medication or acyclovir injection raised the positive predictive value to $99.5 \%$. In addition, we could not exclude the patients who had a previous history of $\mathrm{HZ}$ in this study

In conclusion, the annual incidence of $\mathrm{HZ}$ was increased not only in the total study population but also in all of the age groups from 2010 to 2016 . The seasonality in the occurrence of $\mathrm{HZ}$ was demonstrated, which was the highest in summer.

\section{CONFLICTS OF INTEREST}

The authors have nothing to disclose.

\section{ORCID}

Soon-Hyo Kwon, https://orcid.org/0000-0002-7295-5725

Jung-Im Na, https://orcid.org/0000-0002-5717-2490

In Su Kim, https://orcid.org/0000-0002-2734-6517

Sang-Young Byun, https://orcid.org/0000-0002-1527-1570

Kyoung-Chan Park, https://orcid.org/0000-0002-1588-3307

\section{REFERENCES}

1. Levin MJ. Immune senescence and vaccines to prevent herpes zoster in older persons. Curr Opin Immunol 2012;24: 494-500.

2. Yawn BP, Gilden D. The global epidemiology of herpes zoster. Neurology 2013;81:928-930.

3. HIRA. Statistical information-open system for health and medical big data [Internet]. [cited 2018 Mar 3]. Available from: https://opendata.hira.or.kr.

4. Choi WS, Noh JY, Huh JY, Jo YM, Lee J, Song JY, et al. Disease burden of herpes zoster in Korea. J Clin Virol 2010;47:325-329.

5. Wu PY, Wu HD, Chou TC, Sung FC. Varicella vaccination alters the chronological trends of herpes zoster and varicella. PLoS One 2013;8:e77709.

6. Ogunjimi B, Van den Bergh J, Meysman P, Heynderickx S, Bergs $\mathrm{K}$, Jansens $\mathrm{H}$, et al. Multidisciplinary study of the secondary immune response in grandparents re-exposed to chickenpox. Sci Rep 2017;7:1077.

7. Kim YJ, Lee CN, Lim CY, Jeon WS, Park YM. Populationbased study of the epidemiology of herpes zoster in Korea. J Korean Med Sci 2014;29:1706-1710.

8. Zak-Prelich M, Borkowski JL, Alexander F, Norval M. The role of solar ultraviolet irradiation in zoster. Epidemiol Infect 2002;129:593-597.

9. Kim YS, Seo HM, Bang CH, Lee JH, Park YG, Kim YJ, et al. Validation of herpes zoster diagnosis code in the electronic medical record: a retrospective, multicenter study. Ann Dermatol 2018;30:253-255. 